\title{
Organizations as Communities: Creating Worksite Campaigns to Promote Organ Donation
}

\author{
Susan E. Morgan \\ Purdue University
}

USA

\section{Introduction}

Because workplaces are communities where people spend much of their time-at least half of their waking hours - health educators have long assumed that they would be productive contexts for public education about a wide variety of health issues, including smoking cessation, health screening, and general health promotion, including physical activity, dietary improvements, and multivitamin use (Campbell, et. al, 2002; Emmons, et. al, 1999; Grosch, et. al, 1998; Sorenson, et. al, 2005). Furthermore, worksite campaigns have the potential to reach a greater percentage of a potential audience than a mass media campaign targeting the general public because the audience is "captive" in the workplace. However, using worksites to promote a health issue has often met with mixed results. Success appears to be linked to factors such as the actual reach of worksite activities, participation in activities by employees, the duration and intensity of activities, and whether campaigns target employees who are in greatest need of the intervention (Grosch, et. al, 1998; Orlandi, 1986; Pelletier, 2001).

How worksite campaign successes with other issues can translate to the education of employees about organ donation and transplantation has been largely unexplored. It is important to first consider the ways in which the promotion of organ donation differs from education about other health issues. Unlike smoking cessation, exercise, or injury prevention, becoming an organ donor does not benefit employees, at least not directly or tangibly. To become an organ donor, an employee has to die, and the contemplation of one's own death is not likely to lead to a particularly comfortable cognitive state. Many people's instinctual avoidance of the topic of organ donation itself is an obstacle that researchers and practitioners must overcome when designing an effective worksite campaign. Appeals to employees to become an organ donor must emphasize other benefits, especially the satisfaction of saving the lives of (deserving) others and perhaps even the sense that donors survive death by "living on" through their recipients.

The theoretical foundations of worksite interventions have varied considerably. Theories such as the theory of planned behavior, theory of reasoned action, and the transtheoretical model (a.k.a. the "stages of change" approach) have predominated. However, theories that create a solid foundation for some types of health interventions may not be equally suited to other health issues. This appears to be the case with organ donation, where the 
transtheoretical model has not been used with much success in public communication campaigns to promote organ donation, while the theory of reasoned action (and related models) have proven to be far more useful (see Morgan, 2012, for a review).

A review of the social scientific literature on the predictors of the willingness to donate organs reveals a general consensus that donation-related behaviors are a function of attitudes toward organ donation and toward becoming a donor, knowledge about organ donation (particularly knowledge that counters popular myths about donation), and the importance of the influence of family and friends. These, of course, are the same variables that comprise the theory of reasoned action. There are additional factors that appear to contribute to the willingness to donate, including existential variables such as the perception that organ donors "survive" death, a concern about saving the lives of "bad" people, the fear that signing a donor card will tempt fate and possibly bring on premature death, and a general sense of disgust from the idea of putting the organs from one person into the body of another person (Morgan, Harrison, et. al, 2008; Morgan, Stephenson, et. al, 2008). Morgan and colleagues have added these variables to the theory of reasoned action to create a model (the organ donation model) tailored to organ donation.

The operationalization of these variables has taken the form of specific features of worksite organ donation campaigns. Formative research with both general and minority populations provided important information about the specific points of knowledge that were most predictive of the willingness to donate. These include knowledge about the organ allocation system, the understanding that potential donor status will not affect the quality of medical care in an emergency, knowledge that an organ donor can have an open-casket funeral, and knowledge that a black market does not exist in the U.S. Rather than overwhelm employees with unnecessary general information about organ donation, these worksite campaigns focused on providing details about these specific points of knowledge. This information was printed on cafeteria table tents, appeared in brochures distributed to every employee, and was distributed through paycheck stuffers and email and voicemail blasts.

Organ donation worksite campaigns based on the theory of reasoned action also targeted perceptions of supportive social norms. These campaigns prominently featured employees of organizations who had been touched by organ donation. Donors and recipients were featured on billboards on roads leading to an organization's building as well as full-color posters hung on bulletin boards. Their stories appeared in newsletter articles, which provided greater details about the employees' stories, and abbreviated versions of these stories were used as paycheck/mailbox stuffers. By emphasizing to employees that they all "knew" someone who had been affected by donation, the campaign sought to capitalize on the sense of affiliation that people often feel with their co-workers. Interpersonal discussions about their co-workers' experiences offered the opportunity to exchange personal thoughts and feelings about donation. When this element of a worksite campaign was isolated and tested for its effectiveness, companies with employees personally touched by organ donation experienced greater increases in signed donor cards and/or donor registry forms. Also, the very fact that employees have crowded around an information table in a highvisibility, high-traffic area in the organization to sign up to become a donor becomes a form of social proof may be quite powerful.

Although superstitions about bringing on premature death by signing a donor card or a visceral-level disgust response at the idea of organ transplantation would be difficult at best 
to overcome through a worksite campaign, concerns about the deservingness of potential recipients is more easily addressed. By having transplant recipients help to staff information tables and by featuring a company's own employees in the campaign, most of whom were recipients, non-donors could establish a greater sense of connection with the sort of people who would be potential recipients of their own organs.

Three worksite campaigns will be summarized in chronological order: The United Parcel Service, The University Worksite Organ Donation Project, and The New Jersey Workplace Partnership for Life. Each campaign built upon the lessons learned in previous studies. Greater detail about the statistical evaluation of the outcomes of these campaigns can be found in publications in the social science and medical journals in which they were originally published. It should be noted that all aspects of these campaigns were subject to at least one Institutional Review Board review for ethics. Following the review of campaigns, principles for organizing worksite interventions to promote organ donation will be offered.

\section{The United Parcel Service worksite campaign}

The first example of a successful organ donation worksite campaign took place at United Parcel Service (UPS) during 1999-2000 (Morgan, et. al, 2002). Spearheaded by the Kentucky Organ Donor Affiliates, this worksite organ donation promotion project was a multichannel, multi-message campaign designed to increase knowledge about facts related to organ donation, increase favorable attitudes toward organ donation, increase the rate of signed organ donor cards among audience members, and to increase the willingness of audience members to talk to family members about their decision regarding organ donation.

The worksite organ donation project consisted of a pretest/post-test comparison of two sites of a large, national package delivery corporation. A 10\% stratified random sample was taken from the control and intervention sites, which were located in two separate media markets about a 90-minute drive apart. The intervention component of the project lasted for eight months and utilized multiple message strategies via both mass media and interpersonal channels of communication. The mass media component of the campaign included newspaper articles, notices on the intranet website, billboard ads, and radio PSAs. The interpersonal component of the campaign included educational sessions by the principal investigators, visits by OPO volunteers, and presentation of panels from the organ donor quilt. OPO volunteers staffed tables at the multiple locations at the intervention site several times throughout the campaign, distributing literature, giveaways promoting organ donation, and t-shirts. Volunteers asked employees if they had signed an organ donor card or the back of their driver's licenses, and offered to witness signatures for those who wanted to consent to becoming potential organ donors. Volunteers also shared personal information about their experiences regarding organ donation and answered questions about organ donation facts and processes.

The evaluation of the campaign demonstrated that these strategies were highly effective with a diverse population. Respondents at the intervention site were more likely to sign an organ donor card, have more favorable attitudes toward organ donation generally, and to feel more comfortable about talking to family members about their decision to donate than respondents at the control site. Among those people who had not yet signed an organ donor card, the campaign successfully raised their intention to do so in the future. 
However, there were a number of limitations to the UPS study. First, there was no way of determining which facets of this multi-channel, multi-message campaign produced the strongest effects. Similarly, it was not possible to determine the most cost-efficient means of reaching people with the most powerful message. For example, there was no way to tell how many people accessed the organization's intranet site and read the facts about organ donation. Finally, it was unclear to what degree personal encounters with organ donor recipients or organ donor family members contributed to the traditional means of educating people about organ donation.

\section{The University Worksite Organ Donation campaign}

Because the UPS worksite campaign used only one company and could not pinpoint the campaign elements that contributed to campaign success, a subsequent campaign using six matched worksites was planned, using universities as the sites for two types of campaigns (contrasted against control sites). The University Worksite Organ Donation Campaign was conducted at the University of Arizona, University of Alabama, Rutgers University, Texas A\&M University, University of North Carolina at Charlotte, and Pennsylvania State University. This project represented a more theoretically rigorous test of the campaign strategies initially tested in the UPS campaign. Instead of simply dividing sites into intervention and control, as with the UPS campaign, a third condition was added to test the advantages offered by a full intervention (which included the interpersonal component included in the UPS campaign) over a mass-media-only intervention, which is cheaper and easier to implement, but may ultimately be less effective (Morgan, et. al, 2010).

The campaign heavily utilized internal media including campus papers and faculty/staff newsletters in addition to more traditional outlets such as billboards and radio. In one of the quasi-experimental conditions, only media messages (including those that featured the stories of members of the university community) were used to promote organ donation. In mass media-plus-interpersonal condition, the media campaign was supported by ten on-site visits by OPO staff and volunteers over the course of an academic year.

As with the UPS campaign, a pretest/post-test design was used to evaluate the effects of each type of campaign. A random stratified mail survey demonstrated that compared to the control condition, there was a statistically significant advantage to adding on-site visits on whether respondents reported signing a donor card or talked to family about organ donation. However, the media-only campaign did not produce results that were statistically different from the control condition. The project organizers argue that the outreach component offers community members the opportunity to "put a human face" on the issue of organ donation because many volunteers are transplant recipients or donor family members. Additionally, the site visits provide an opportunity to ask questions about organ donation that may linger even after seeing ads or billboards promoting organ donation.

Because universities are large employers that are present in every state, offer their own set of media outlets (including newspapers and radio stations), and are effectively matched on a number of vital characteristics, they are an ideal set of organizations to test these campaign principles. However, it is difficult to generalize to worksites that are not university-based. Universities tend to employ a greater proportion of well-educated people than most employers. University worksites are also comprised of a large number of buildings housing employees, which creates difficulties in reaching employees in one (or just a few) centralized 
locations. In addition, a year-long campaign such as the one conducted at university worksites is probably not feasible for most OPOs and their workplace partners.

\section{The New Jersey Workplace Partnership for Life}

In order to test the generalizability of the findings of the University Worksite Organ Donation Campaign with a wider variety of organizations, a larger-scale series of worksite campaigns was developed in New Jersey (Harrison, in press; Morgan, Harrison, et. al, 2010). This project reached over 30,000 employees in 45 companies in industries including health care, pharmaceuticals, manufacturing, law, education, and municipalities. Companies were divided into three quasi-experimental conditions that replicated those of the University Worksite Organ Donation Project (mass media campaigns contrasted against campaigns that also included on-site visits by staff and volunteers). In addition to expanding the number and diversity in the type of companies reached, campaigns were reduced to a 10 week time period.

In addition to "myth buster" messages designed to educate employees about the most common misconceptions about organ donation, companies in the mass media condition publicized the stories of co-workers who had been touched by organ donation. About half of all companies had employees willing to share their stories; in the event that an employee story was not available, stories about people in the same industry or the same town were used instead to maximize a sense of affiliation. All media messages were disseminated through internal (not external or paid) media, including email, cafeteria table tents, newsletters, posters, paycheck stuffers, and LCD boards.

Depending on the size of the company, which ranged from 100 employees to nearly 4,000 employees, on-site visits to companies in the high-intensity campaign group were conducted 3-4 times over the course of the 10-week campaign. Tables were set up in hightraffic locations, including lobbies and cafeterias and were typically staffed by two project team members and a volunteer from the organ procurement organization, usually a transplant recipient. A panel from the state's donor family memorial quilt was on display to further promote a sense of personal connection with the issue. Small giveaways such as pens, magnets, and sticky note pads helped to attract attention to the table, where staff members then used a set script to engage employees in a discussion about any questions about donation or the state's organ donor registry.

Results from pretest/post-test surveys of a random sample of employees confirm previous findings that campaigns which include on-site visits are more successful than those that use only internal media to disseminate information about organ donation. Mass media campaigns, which utilized only internal forms of media (newsletters, posters on bulletin boards, paycheck stuffers, etc.) increased the rate of donation among non-donors by an average of $13.6 \%$.

\section{Best practices for Worksite Organ Donation campaigns}

A blueprint for successful campaigns (from both a pragmatic as well as theoretical point of view) is slowly emerging. While it is ideal practice to ground interventions on a theory of behavior change, it is probably sufficient for practitioners to simply follow in the footprints of previous campaigns as closely as possible. Similarly, the effectiveness of any campaign 
requires evaluation of audience members' knowledge, attitudes, and beliefs before and again after the campaign and to compare these results to a matched control group (generally, an organization of similar size and composition). Again, a full evaluation may be outside of the realm of possibility for most practitioners, but a brief survey of, for example, the number of people who have definitively committed to becoming a potential organ donor before the campaign and again after the campaign would provide a reasonably good means of measuring whether the campaign succeeded in its goals.

One type of campaign practice that many practitioners appear to find difficult to resist (in part because managers of organizations generally offer access to this channel the most readily, often to the exclusion of other channels) is the "lunch and learn." In this format, campaign staff show up to an appointed conference room or other meeting space during the lunch hour and present information about organ donation to employees who are interested in learning more about organ donation. As one might expect, the people who need accurate information about organ donation the most (in other words, people who are the most likely to believe in common myths about donation) are also the least likely to voluntarily attend such a meeting. Additionally, any „improvements" noticed in donation-related outcomes (such as donor registrations) are likely to be very small and only among people who were already inclined toward such behaviors.

Fortunately, it is entirely posssible to replicate successful worksite campaigns. Worksite campaigns that include the following six elements are more likely to result in a greater number of donor registrations.

First, it is important to utilize both mass media and interpersonal communication channels. Messages distributed through each channel will have strengths and weaknesses that can be compensated for by messages delivered through the other channel. Mass-produced educational materials (such as educational brochures) should have high production values; otherwise, the credibility of the campaign can be called into question. However, no matter how well produced, messages delivered through mass media channels (including emails, posters, etc.) can seem impersonal. Moreover, they lack the ability to be tailored to each individual employee's personal misgivings about donation. This is why on-site visits by trained staff members and/or volunteers are of central importance. From experience, the ideal number of visits should be 2-3, spaced about 2-3 weeks apart over a 6-9 week period to maximize the effect of the educational intervention by offering opportunities to address concerns about donation in person while avoiding "intervention fatigue“ by employees and management.

Second, having access to multiple intra-organizational communication channels will support the success of a worksite campaign for a couple of reasons. Not only are these channels free, but the use of these channels signals to employees that the campaign is being supported by top management. Intraorganizational "mass"communication channels that are frequently used include company intranet websites, newsletters, company mail, email, voicemail, and bulletin boards in hallways, stairwells, and breakrooms (for posters).

Third, whenever it is possible, solicit employees' own stories about how they (or close family members) been touched by organ donation, either because they (or a loved one) received an organ transplant or because someone close to them died and became a donor. These stories can be featured in campaign materials to great effect. Not only do they 
personalize the issue of organ donation and make it more "real“ to employees, these stories identify a readily identifiable point-person for employees to talk to about donation. However, it is good idea to ensure that these informal "spokespeople" are reasonably knowledgeable about donation before the campaign begins.

Fourth, the ability to conduct on-site visits in high-visibility, centrally-located gathering places is of great importance to the success of worksite campaigns. Not only does a central location help to maximize the likelihood that all employees will be exposed to campaign messages and have the opportunity to interact with campaign staff, it also helps to create „buzz“ about the campaign among employees. The more you can gather people around an information table to talk to staff, the more likely it is that other employees will want to listen or talk. To increase the chances that people will come over to an information booth or table, it is important that staff members do not sit (unless medically necessary) and that they distribute something that is perceived to be useful or interesting that is free. (There are many low-cost giveaways available through numerous vendors. Pens are popular for good reason. Check samples from vendors to make sure they write well. No one likes a lousy pen.)

Fifth, the use of well-trained volunteers who follow scripts on how to address the most common concerns about organ donation will ensure that myths about donation are "busted" smoothly and convincingly. Although there is a line of thought that simply sharing „personal stories" about transplant experiences will motivate members of the public to commit to donation, there is ample evidence that knowledge already exists about the need for donation as well as the life-saving potential of organ donation; sharing personal stories does not overcome the most common objections to becoming a potential organ donor. In other words, stories must be accompanied by information that is specific to each individual employee's concerns. Teaching staff and volunteers how best to quickly and succinctly disseminate information about donation in response to common inquiries is a far more effective strategy. Numerous manuals for training staff and volunteers on communication protocol are available by request from volunteer coordinators working for organ procurement organizations in the U.S.

Sixth, because worksite interventions represent a significant investment of time and energy, it is best to concentrate efforts on large organizations of 500 employees or more. Donation is a low-incidence event; the likelihood that any one individual will become a potential donor is very low. Currently, only about 1 in 100 people die in such a way that they would be eligible to become an organ donor. Without any public education intervention at all, about half of eligible donors have either already declared their wishes to donate or their family members will consent to donation in the absence of documentation of their deceased loved one's wishes. Thus, a large number of people need to be reached effectively with a campaign to increase the actual number of donors by even one person.

\section{Costs associated with worksite campaigns}

Although worksite campaigns can be conducted in a way that minimizes direct financial expenditures, there are other types of costs that must be considered. The largest cost for campaign organizers is time. Potential worksites to host a campaign must be selected, after which possible appropriate contacts to correspond with about the project. Next, meetings have to scheduled to do an initial presentation of the campaign and its goals. A second 
round of meetings with "gatekeeping" managers (and union representatives, where applicable) is inevitable, particularly with the largest organizations. Organizations with unionized employees will require the permission and involvement of unions in order to gain permission to distribute printed materials, for example, and may present a set of complications that are difficult to forsee. (Involving national leaders of unions may prove to be an investment of time that can be worthwhile if a campaign targets organizations within the same industry, such as auto manufacturing.)

Meetings are not the only expenditure of time involved with the development of a worksite campaign. The process of creating and tailoring campaign messages can involve a significant investment of time. Similarly, the process of arranging for the distribution of these messages can take many hours. Training, scheduling, and supervising volunteers and/or staff members is an ongoing commitment. Finally, creating a final report for the organization reporting on activities and outcomes (such as number of new donor registrations) is an important deliverable that is valued by many organizations.

Time is one type of intangible expense associated with worksite campaigns. Opportunity costs are another type. The energy expended on organizing and executing a worksite campaign is energy that cannot be devoted to other types of activities that could also advance donation. Thus, it is important to invest time wisely.

Additionally, there are still a few direct financial costs for a worksite campaign which can be detailed. First, educational materials for all employees should be printed. Even at pennies or centimes per print, printing charges will add up if an organization has thousands of employees. Second, incentives for employees to visit an information table staffed by volunteers (or paid staffers) will need to be purchased. Small giveaways are usually colorful and attract attention and can provide an excuse for volunteers to begin a conversation with a line like, „We're talking to people about donation today. Have you considered registering as a potential organ donor? Third, direct costs are often incurred by campaigns if they reimburse staff members for mileage or gasoline as well as meals during the time that they work. (These same costs are incurred during the training process for volunteers who are willing to work for this type of campaign.)

Finally, it can be a good practice to give a token gift to the organizational liaison who has worked with your team to coordinate campaign activities and the dissemination of educational materials. Many people readily agree to help and quickly discover that the job is bigger than they had anticipated. If you would like to build a list of references that you can provide to future potential worksite campaign locations, it may be a wise investment to make sure your liaisons think of you fondly.

Gaining (and maintaining) access to large organizations for worksite campaigns appears to be the principal challenge facing these campaigns, which nevertheless hold the promise of reaching many thousands of people with organ donation information as well as easy opportunities to become potential organ donors.

\section{Conclusion}

In conclusion, worksite organ donation campaigns hold considerable promise for the future. “One important finding [from worksite campaigns]...is that [they]... may be more powerful 
in increasing the target behavior of individuals... Such group interventions are also certainly more cost-effective than individual interventions. Worksite programs take advantage of social support, peer influence, and preexisting group loyalties, which may be important because people often find behavior change difficult on their own" (Perkins, 1990, p. 182). Professionals seeking to disseminate compelling and accurate information about organ donation would do well to conduct worksite campaigns not only because they provide a large "captive audience" for information about organ and tissue donation and the importance of talking to family members about their donation decisions, but because information can be framed in ways that matter to employees.

\section{Acknowledgments}

The author would like to acknowledge the excellent contributions of the many people who have helped to create and evaluate the successful worksite campaigns discussed in this chapter. They include Tyler Harrison, Jenny Miller Jones, Lisa Volk Chewning, Tara Artesi, Jessica Melore, Michael Stephenson, Walid Afifi, Shawn Long, Tom Reichert, Tom Cannon, and the many extraordinary volunteers whose lives have been touched by organ donation.

\section{References}

Campbell, M.K., Tessaro, I., DeVellis, B., Benedict, S., Kelsey, K., Belton, L. (2002). Effects of a tailored health promotion program for female blue-collar workers: Health works for women. Preventive Medicine, 34, 313-323. ISSN 0091-7435

Emmons, K.M., Linnan, L.A., Shadel, W.G., Marcus, B., \& Abrams, D.B. (1999). The working healthy project: A worksite health promotion trial targeting physical activity, diet, and smoking. Journal of Occupational and Environmental Medicine, 41, 545-555. ISSN 1076-2752

Grosch, J.W., Alterman, , T., Petersen, M.R., \& Murphy, L.R. (1998). Worksite health promotion programs in the U.S.: Factors associated with availability and participation. American Journal of Health Promotion, 13, 37-45. ISSN 08901171

Harrison, T. R., Morgan, S. E., Chewning, L. V., Williams, E., Barbour, J., Di Corcia, M., \& Davis, L. (in press). Revisiting the worksite in worksite health campaigns: Evidence from a multi-site organ donation campaign. Journal of Communication. ISSN 00219916

Heaney, C A. Goetzel, R Z. (1997). A review of health-related outcomes of multi-component worksite health promotion programs. American Journal of Health Promotion. 11(4):290-307. ISSN 08901171

Morgan, S.E. (2012). Public communication campaigns to promote organ donation: Theory, design, and implementation. In R. Rice and C. Atkin (Eds.) Public communication campaigns. Thousand Oaks, CA: Sage Publications. ISBN 9781412987707

Morgan, S.E., Harrison, T.R., Long, S.D., Afifi, W.A., \& Stephenson, M.T. (2008). In their own words: A multicultural qualitative study of the reasons why people will (not) donate organs. Health Communication, 23, 23-33. ISSN 1041-0236.

Morgan, S.E., Harrison, T.R., Chewning, L.V., DiCorcia, M.J., \& Davis, L.A. (2010). The Workplace Partnership for Life: The effectiveness of high- and low-intensity worksite campaigns to promote organ donation. Communication Monographs, 77, 341-356. ISSN 0363-7751 
Morgan, S.E., Miller, J., \& Arasaratnam, L.A. (2002). Signing cards, saving lives: An evaluation of the Worksite Organ Donation Promotion Project. Communication Monographs, 69, 253-273. ISSN 0363-7751

Morgan, S. E., Stephenson, M. T., Harrison, T. R., Afifi, W.A., \& Long, S.D. (2008). Facts versus "feelings": How rational is the decision to become an organ donor? Journal of Health Psychology, 13, 644-658. ISSN 1359-1053

Morgan S.E., Stephenson M.T., Afifi W., Harrison T.R., Long S.D., \& Chewning L.V. (2010). The University Worksite Organ Donation Project: a comparison of two types of worksite campaigns on the willingness to donate. Clinical Transplantation, 25, 600605. ISSN 0902-0063

Orlandi, M.A. (1986). The diffusion and adoption of worksite health promotion innovations: An analysis of barriers. Preventive Medicine, 15, 522-536. ISSN 0091-7435

Pelletier, K.R. (2001). A review and analysis of the clinical and cost-effectiveness studies of comprehensive health promotion and disease management programs at the worksite: 1998-2000 update. American Journal of Health Promotion, 16, 107-116. ISSN 08901171

Perkins, K. A. (1990). Applicability of health promotion strategies to increasing organ donation. In J. Shanteau \& R. J. Harris (Eds.), Organ donation and transplantation: Psychological and behavioral factors. Washington, DC: American Psychological Association. ISBN 978-1557980793

Sorensen, G., Barbeau, E. Stoddard, A.M., Hunt, A.K., Kaphingst, K., \& Wallace, L. (2005). Promoting behavior change among working-class multiethnic workers: Results of the health directions-small business study. American Journal of Public Health, 95, 1389-1395. ISSN 0090-0036 


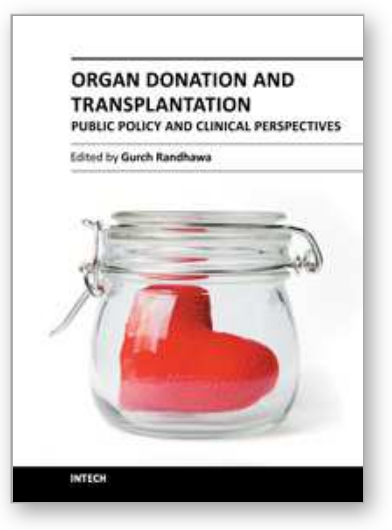

\author{
Organ Donation and Transplantation - Public Policy and Clinical \\ Perspectives \\ Edited by Dr. Gurch Randhawa
}

ISBN 978-953-51-0039-3

Hard cover, 284 pages

Publisher InTech

Published online 08, February, 2012

Published in print edition February, 2012

Transplantation has succeeded in prolonging the lives of those fortunate enough to have received the gift of a body organ. Alongside this life-saving development, there lies another sadder side to the story - there are not enough organs to meet the ever increasing demand. This not only places an increasing emotional and physical burden among the waiting patients and families but heaps a great financial burden upon health services. This book provides an analysis and overview of public policy developments and clinical developments that will hopefully ensure an increased availability of organs and greater graft survival. Medical, policy, and academic experts from around the world have contributed chapters to the book.

\title{
How to reference
}

In order to correctly reference this scholarly work, feel free to copy and paste the following:

Susan E. Morgan (2012). Organizations as Communities: Creating Worksite Campaigns to Promote Organ Donation, Organ Donation and Transplantation - Public Policy and Clinical Perspectives, Dr. Gurch Randhawa (Ed.), ISBN: 978-953-51-0039-3, InTech, Available from: http://www.intechopen.com/books/organ-donationand-transplantation-public-policy-and-clinical-perspectives/organizations-as-communities-creating-worksitecampaigns-to-promote-organ-donation

\section{INTECH}

open science | open minds

\section{InTech Europe}

University Campus STeP Ri

Slavka Krautzeka 83/A

51000 Rijeka, Croatia

Phone: +385 (51) 770447

Fax: +385 (51) 686166

www.intechopen.com

\section{InTech China}

Unit 405, Office Block, Hotel Equatorial Shanghai

No.65, Yan An Road (West), Shanghai, 200040, China

中国上海市延安西路65号上海国际贵都大饭店办公楼 405 单元

Phone: +86-21-62489820

Fax: +86-21-62489821 
(C) 2012 The Author(s). Licensee IntechOpen. This is an open access article distributed under the terms of the Creative Commons Attribution 3.0 License, which permits unrestricted use, distribution, and reproduction in any medium, provided the original work is properly cited. 